\title{
Understanding and supporting women with polycystic ovary syndrome: a qualitative study in an ethnically diverse UK sample
}

\author{
Michelle Hadjiconstantinou ${ }^{1}$, Hamidreza Mani ${ }^{1,2}$, Naina Patel ${ }^{1}$, Miles Levy ${ }^{2}$, \\ Melanie Davies ${ }^{1,2}$, Kamlesh Khunti ${ }^{1}$ and Margaret Stone ${ }^{1}$ \\ 'University of Leicester, Diabetes Research Centre, Leicester Diabetes Centre, Leicester General Hospital, \\ Leicester, UK \\ ${ }^{2}$ Department of Diabetes and Endocrinology, Leicester Royal Infirmary, University Hospitals of Leicester \\ NHS Trust, Leicester, UK
}

Correspondence

should be addressed

to H Mani

Email

hamidreza.mani@uhl-tr.nhs.uk

\begin{abstract}
Objective: Polycystic ovary syndrome (PCOS) is a lifelong condition. Its symptoms have been linked with psychological consequences, but less attention has been given to the daily implications of living with PCOS. We aimed to explore women's experiences living with PCOS, and the potential acceptability of group education sessions for this target group.

Methods: Women with PCOS were recruited from an ethnically diverse UK community. Twelve semi-structured interviews were conducted. Analysis was underpinned by the constant comparative approach and involved the identification and exploration of key themes.

Results: Participants reported a range of symptoms linked with PCOS, including problems relating to menstruation and weight difficulties. Hirsutism was reported as the most distressing symptom. Emergent themes included perceptions about symptoms and delays in receiving a diagnosis; psychological distress; practical implications of living with the condition; coping with PCOS and perceived support needs. Some findings were specific to cultural backgrounds. Participants were supportive of the idea of group education for women with PCOS and suggested a need to provide education within the community and health care providers.

Discussion: Women with PCOS experience high psychological distress and difficulties with coping with their condition. Suggested strategies to reduce the negative psychological impact include education at various levels.
\end{abstract}

Key Words

- polycystic ovary syndrome

- quality of life

- wellbeing

- multi-ethnic
- qualitative

\section{Introduction}

Polycystic ovary syndrome (PCOS) is the most common endocrine condition in women (1). It can have important consequences in relation to both physical and mental health $(2,3,4)$ and increase the risk of type 2 diabetes (T2DM), hypertension and cardiovascular diseases, as well as contributing to overall poor wellbeing $(5,6,7)$. Previous studies have highlighted challenges faced when managing $\operatorname{PCOS}(5,8,9,10,11)$ including feeling 'abnormal' or like a 'freak' (12). Lack of information given to women diagnosed with PCOS may also create confusion about why they are experiencing symptoms, leading to feelings of guilt and lack of control $(4,12,13)$.
Endocrine Connections (2017) 6, 323-330

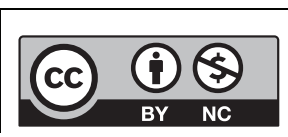

This work is licensed under a Creative Commons Attribution-NonCommercial 4.0 International License. 
It is clear that a diagnosis of PCOS has important psychological consequences, but less consideration has been given to more practical implications relating to day-to-day living and to ways of supporting women with the condition. We aimed to confirm previous findings in an ethnically diverse population, but also to broaden the scope of current knowledge regarding experiences and support needs. On a practical level, our study specifically aimed to explore the potential acceptability of group education sessions for women with PCOS and to inform the process of refining the content of a proposed education programme (Clinical Trials.Gov registration number NCT01462864).

\section{Subjects and methods}

Ethics committee approval was obtained (11/EM/0141). The study involved semi-structured interviews and the overall methodology was informed by the constant comparative approach (14). The position adopted in our study was primarily pragmatic, linked to health services research, in line with our focus on provision of effective support for women with PCOS.

\section{Setting and recruitment}

The study was conducted in Leicestershire, UK, an area characterised by ethnic diversity. People of south Asian (mainly Indian) origin are strongly represented (15). Sampling was purposive, aimed at recruiting women with PCOS who could potentially contribute to our exploration of experiences and views about support. On this basis, women with a clear diagnosis of PCOS based on Rotterdam criteria (16) were eligible to participate. Participants were mostly recruited from a local hospital by advertisement or initial approach at outpatient clinics, but also included three local women who approached the research team after learning about the study. After twelve interviews, it was determined that a good level of saturation had been reached in terms of the emergence and adequate exploration of relevant themes.

\section{Data collection}

One interview was conducted in the participant's home, two at their work place and the remainder in the hospital outpatient clinic. Participants provided written informed consent. Semi-structured interviews (c) 2017 The authors Published by Bioscientifica Ltd
Table 1 Summary of topics included in the topic guide.

- Experiences and feelings related to diagnosis and symptoms

- Advice, treatment and support received and knowledgeseeking behaviour

- Understanding and attitudes relating to the condition

- Experience of living with the condition, including feelings about control

- Feelings about attending an education session, including format

were conducted ( $\mathrm{H}$ M or N P) using a flexible topic guide (Table 1) to ensure that data relevant to the aims of the study were gathered, whilst leaving scope for additional themes to emerge using open questions. All participants were comfortable with discussing their condition in English. The mother of the youngest participant (aged 17) attended the interview with her daughter. The interviews were audio-recorded and transcribed verbatim.

\section{Analysis}

Analysis involved identification and exploration of themes, including development of a coding framework. With the use of the NVivo package (qualitative data indexing software), a process of charting based on the framework approach (17) was followed to facilitate data collation and exploration across and between cases and themes. Throughout the process of analysis, the focus of the study regarding the development of an educational intervention was kept in mind, whilst also considering the broader issue of participants' experiences of living with PCOS (14). The source data were reviewed on an ongoing basis by two independent reviewers (M S and $\mathrm{M} \mathrm{H}$ ), to ensure that emerging findings were consistent with the interviews and thus grounded in the data.

\section{Results}

\section{Sample and key themes}

Our sample comprised 12 women (age range of 17-51 years; seven white British, four south Asian and one black African). Participants reported a range of symptoms regarded as being definitely or possibly attributable to PCOS, with a majority describing hirsutism $(n=11)$, problems related to menstruation and/or infertility $(n=11)$ and difficulties with weight $(n=10)$ (Table 2$)$. Key emergent themes are described below, including differences linked to the ethnic background of participants. http://www.endocrineconnections.org DOI: 10.1530/EC-17-0053
This work is licensed under a Creative Commons Attribution-NonCommercial 4.0 International License. 
Table 2 Characteristics of participants.

\begin{tabular}{|c|c|}
\hline Participant characteristics & Total $(n=12)$ \\
\hline \multicolumn{2}{|l|}{ Symptoms* } \\
\hline Hirsutism & 11 \\
\hline Irregular or heavy periods & 11 \\
\hline Weight gain/difficulty maintaining weight & 10 \\
\hline Infertility & 4 \\
\hline Acne & 3 \\
\hline Tiredness & 1 \\
\hline Mood swings & 1 \\
\hline Skin discoloration & 1 \\
\hline \multicolumn{2}{|l|}{ Distribution within age range } \\
\hline $17-27$ & 3 \\
\hline $28-37$ & 2 \\
\hline $38-47$ & 4 \\
\hline $48-57$ & 1 \\
\hline \multicolumn{2}{|l|}{ Ethnicity (self-identification) } \\
\hline White/Caucasian & 7 \\
\hline South Asian & 4 \\
\hline Black African & 1 \\
\hline \multicolumn{2}{|l|}{ Age/time of diagnosis } \\
\hline Early - Mid teens & 3 \\
\hline Early - Mid 20s & 5 \\
\hline Early - Mid 30s & 1 \\
\hline Early - Mid 40s & 3 \\
\hline
\end{tabular}

*Symptoms described in varying degrees of severity and as being definitely or possibly linked to PCOS.

\section{Symptoms and delays in diagnosis}

Participants acknowledged that the symptoms described are not exclusive to women with PCOS, for example, menstrual problems and weight gain:

'... there have been some days, some months, where my period starts and just the idea of getting out of bed and going into work is just an absolute no-no. But I don't know whether that happens for other people sometimes anyway.' (Participant 9 , age 40$)$.

'I'm not sure whether it (weight gain) is just related to PCOS or whether it's because of my thyroid.' (Participant 10, age 45$)$.

One south Asian participant reported that she had at first considered her symptoms as normal for a woman from her background:

'Tiredness, heavy periods, which I took as normal, extreme hair growth which, as an Asian person, I took as normal.' (Participant 7, age 51).

There was a variation in terms of how long it had taken for PCOS to be diagnosed, with some women attributing delays to health care providers' failure to recognise the condition:

'... I said to him "I think I've got polycystic ovaries", but he didn't understand what I was talking about, he didn't know, I could just tell he didn't know what I was talking about. I said
"I'm getting facial hair and I'm putting on a lot of weight an I'm having like just two or three periods"... and then he said to me to go and do a pregnancy test, maybe I'm pregnant, that's why I'm not having no periods. So I just realised he didn't understand a lot about it.' (Participant 1, age 28).

In some instances, participants also linked delays to their own behaviour. One described how she had delayed taking any action despite her suspicions:

'... it's always kind of been in the back of my head or maybe I have it. But never really done anything about it, and then my periods became a lot lighter... I never had a regular period and that's when I thought maybe I need to get something sorted about this, you know. I thought because it wasn't an ailment it's not like I'm ill from it, I never thought the doctors would really be that bothered.' (Participant 11, age 26).

Another participant attributed her reasons for delay to other health problems and embarrassing symptoms:

'... because I've got a number of other problems as well, to be honest it was just another thing, and because I was highly, highly embarrassed, highly embarrassed, you know, and I just didn't say anything. Just got on with it until I couldn't bear it anymore.' (Participant 2, age 44).

\section{Psychological distress}

Concerns about infertility were described as a source of anxiety:

'... not being able to have kids when I was older, that was my main worry really (when diagnosed).' (Participant 4, age 17).

'We (partner and self) both got slight niggles at the back of the mind that it might be harder to get pregnant ... I think because you are not having periods automatically that's like a red flag to become pregnant obviously.' (Participant 12, age 29).

Participants also described how symptoms such as weight gain had influenced self-image and self-esteem:

'... when I did want to wear anything nice I didn't have anything nice to wear anyway because I was too fat to have anything nice.' (Participant 10, age 45).

Hirsutism was particularly distressing, described as leading participants to feel 'like a freak' (Participant 3) or make negative comparisons between themselves and other women:

'I used to get quite down with that (hirsutism), because it was something, I've got sisters as well and obviously even comparing myself to my sisters they didn't have anything like that and it really did upset me.' (Participant 5, age 29).

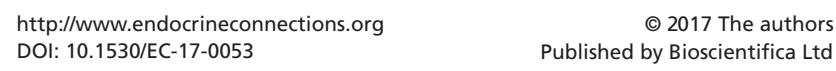


Participants described anxiety and distress related to their perceptions about lack of control within their lives:

'I don't have control over it, it controls me sometimes, I feel.' (Participant 6, age 43).

'I was always somebody who felt like I had control over my body I suppose and so suddenly there was something that I couldn't control any more. And I suppose linked to that, yes, just the weight thing is just - I look at, even now, I look at myself in the mirror and I think "Ugh, not good".' (Participant 9, age 40).

In some cases, feelings related to stigma were perceived as being influenced by cultural norms. One participant suggested that infertility was a particular problem for women from her cultural background. She also described how cultural attitudes influenced the way in which she felt about hirsutism as an African woman living in the UK, where excess hair is less acceptable:

'... it's not normal for a woman not to, to have (children), especially in African cultures it's like taboo. I can say like you might be cast out if you can't have any children and people call you names and say things like that. But with the facial hair, in Africa it's okay because a lot of women have it. It's just here in England ... you have to shave your legs and you have to shave this and that, when back home it's not like that.' (Participant 1, age 28).

Anxiety about health-related consequences of PCOS, particularly increased risk of type 2 diabetes, was also mentioned:

'I know you're at a high risk of diabetes as well, I think ... It is something that, you know, is a bit of a worry.' (Participant 8 , age 26 ).

It was noted, however, that one south Asian participant felt that the high overall prevalence of diabetes in south Asians meant that increased risk specific to PCOS was less relevant for her. In this way, she sought to rationalise her lack of concern:

'Oh I don't worry about that (increased risk of diabetes) ... I think that it will lead to that anyway, because just about every family member has got diabetes in my family.' (Participant 7 , age 51).

\section{Impact on day-to-day living}

Some participants described how reduced self-confidence and self-esteem affected social and personal interactions:

'I didn't confide in anybody ... in fact I sort of withdrew into myself a bit more as I got older, yes. I sort of dropped a lot of my friends ... when you meet people, you sort of, you don't engage properly. You can't look at people because then people look at your (hairy) arm and you think people are looking too closely...' (Participant 6, age 43).

'... I have two or three friends that I will see regularly, but I don't go out as much as I used to and I think some of that .... I don't feel good enough about myself ... (I've) had lots of discussions (with partner) about that and the impact it has on my overall confidence which then has an impact on our sexual relationship because I don't feel confident, I don't feel sexy so why would anybody else think I look sexy...' (Participant 9, age 40).

Although the majority of participants reported that having PCOS did not affect them in relation to employment, one participant also described how problems with hirsutism had caused difficulties in her work role:

'... working with children, I'm told to pull my hair up, so then I always have to make sure in my interviews I tell then beforehand that I can't pull my hair up because I've got polycystic ovaries and I've got facial hairs and I don't want everybody to see it because it makes me feel uncomfortable. So a few of the places they were okay with it ... but then I feel really bad because of the parents and they want to be able to see my face when I'm talking to them about their children.' (Participant 1, age 28).

An additional practical implication of having PCOS was the high cost of laser hair removal treatment:

'... this is only recent that I've been having laser (treatment) because it's quite expensive and at that time (when studying), it's not available on the NHS, so I couldn't afford that much money ...' (Participant 5, age 29).

\section{Coping strategies}

In addition to personal strategies for hair removal including shaving and laser treatment, some participants described pharmacological therapy including the contraceptive pill, spironolactone and metformin, although there was some variation in terms of the perceived effectiveness of these medicines:

'I've gone on to the pill ... which I think helps block the male hormone so and my skin has got a little bit better and my hair growth isn't so fast now as well, so it is working.' (Participant 8, age 26).

'I'm on metformin already. I don't know if it's helped (with weight problem) or not ... maybe it is working, I don't know.' (Participant 7, age 51).

One south Asian participant, highlighted a potential cultural issue regarding the contraceptive pill, which she described as 'taboo' for unmarried girls in her community:

$$
\begin{aligned}
& \text { http://www.endocrineconnections.org } \\
& \text { DOI: 10.1530/EC-17-0053 }
\end{aligned}
$$

๑ 2017 The authors Published by Bioscientifica Ltd
This work is licensed under a Creative Commons Attribution-NonCommercial 4.0 International License. 
'I'm from an Asian family, where obviously he [doctor] did say it was a contraceptive pill and that's a very taboo thing for an unmarried girl to be taking, a contraceptive pill.' (Participant 5, age 29).

Some participants described psychological coping strategies, including denial or trying 'not to think about it' (Interview 1). Acceptance and moving on with life were perceived as being helpful for coping with a chronic condition:

'... learning to accept what you've been diagnosed with and, you know, that it is then part of you ... PCOS is something that once you're diagnosed, it's not like a cold or a temperature that after $24 \mathrm{~h}$ it will go away. It's there with you for the rest of your life.' (Participant 3, age 51).

'I still find it upsetting and distressing and it does plague my life with what I want to do, but I really have now thought to myself "no, I have to get on with it for my own sake".' (Participant 2, age 44).

'I do just have to just cope and just get on with it a lot of the time and just trying to reverse psychology myself ... and just get on with it.' (Participant 11, age 26).

Some described undertaking their own research via books or the internet, in order to better understand the condition. Two participants reported that they had joined the PCOS self-help group verity (www.verity-pcos.org.uk).

\section{Support needs}

Emotional support was seen as important, but participants varied in terms of how much family support they had received. Some reported that they had not sought this type of help because they were uncomfortable about discussing their condition with family members or that the quality of support offered was limited by poor understanding:

'(I've told) no-one, absolutely no-one ... (due to) embarrassment ... No, I've never said anything to any of my family, not even my partner now of nine years, ever.' (Participant 2, age 44).

'Oh he (husband) is aware of it (PCOS) because I go to the hospital appointments and I tell him, and then I started tablets, which he doesn't like ... I tell him about them, but I don't think he a hundred percent understands ... (feeling tired) affected us quite a bit, not being able to go out late at night and things like that, very tired. So I think it would have been nice for him to accept and support that a bit more, but he has no understanding of polycystic ovaries at all, nothing.' (Participant 7, age 51).

Good support from health care providers was seen as essential, including the importance of having someone to listen to any concerns and facilitate understanding of PCOS:

'I don't know, to be taken seriously and to be listened to and actually just to be walked through the process and told "actually you're not going to die from it. It's something that you're going to have to learn to cope with. Have strategies to deal with. And, yes, it may be difficult for you to have kids but it's okay because when you get to that stage there may be things that we can do for you. You may have problems losing weight but how about trying this strategy? How about trying a low GI (diet), how about trying lots of exercise?".' (Participant 10 , age 45$)$.

However, participants varied in terms of how much support of this type they had actually received from health care providers and there were positive feelings about the idea of having a specialist PCOS support nurse:

'They've been helpful ... just answering the questions that you've got, and just ... reassuring.' (Participant 4, age 17).

'I feel like the access that you get to support and advice is not really around. I feel like there should be follow-up once you have been diagnosed ... I don't know if there is such a thing as a specialist PCOS nurse or someone that can talk you through it and go through your symptoms and how you can manage those symptoms. Maybe put a plan in place of how often you need to be reviewed depending on how severe your symptoms are, that would be good.' (Participant 12, age 29).

The benefits of peer support from other women with PCOS were widely recognised:

'It was nice, I went to one of their (Verity support group) meetings, they had a conference type thing, and I went to that and it was nice to actually talk to some other people who had got it and, you know, some of them had had it for several years and, you know, were just getting on with it sort of thing. And some people very similar to me and sort of only recently been diagnosed.' (Participant 9, age 40).

\section{Support through education}

Participants were supportive of the idea of education sessions for women with PCOS, particularly when first diagnosed. It was felt that such sessions could provide support by increasing knowledge and understanding and also by providing an opportunity to share experiences.

'I think, for me, the encouragement (to go to a group education session) would be to meet somebody else that has it, so it's common ground then isn't it. Something that you can discuss with somebody else who knows how you kind of feel.' (Participant 8, age 26). http://www.endocrineconnections.org
DOI: 10.1530/EC-17-0053
(C) 2017 The authors Published by Bioscientifica Ltd
This work is licensed under a Creative Commons Attribution-NonCommercial 4.0 International License. 
One south Asian participant suggested that, for providing optimal psychological benefit, peers may need to be more closely similar than just sharing a diagnosis of PCOS, for example, in terms of similar age and shared cultural background:

'There was a lady once at the hospital, she sort of started a group thing. I did come once or twice, but they were all English ladies, there was no-one looking like me, and they were all a bit older than me ... I think I would have gone if there had been other like Asian people or, you know, Mediterranean people or somebody, and maybe sort of around in your age range.' (Participant 6, age 43).

Two participants felt that a group format might not suit them personally, because of their concerns about privacy, although they recognised that other women might benefit:

'I'm not too happy about the group thing ... It's just me, I'm just a very, I don't know ... it's better in a group, I know that, it's just me personally.' (Participant 2, age 44).

'... obviously the people who have been diagnosed with PCOS are probably going through the same things that I am ... but it would be on the basis that I don't know anybody in the room and they don't know me and once we leave the hospital, or wherever the meeting is, you go your own way.' (Participant 3 , age 51).

Participants also suggested that there was a need for education about PCOS at a wider level than just for women with the condition. They felt that it would be beneficial to raise knowledge and awareness in health care providers as well as in family members and in the wider community, including schools:

'Doctors (also need education). I felt, and I know it sounds really awful, but I did feel really kind of that she didn't, they (symptoms) didn't really matter because it wasn't physical, it didn't really matter, because I had already been, you know, I had already fallen pregnant and I don't need to worry about it. I just did think that she kind of just liked pushed it off a little bit like it didn't really matter.' (Participant 11, age 26).

'I feel like men (partners of women with PCOS) need to know, you know. They need to know about different things that women go through, like if I can't fall pregnant ... It's actually a condition, like I've got a condition and something's actually happening.' (Participant 1, age 28).

'(Having information) in doctors' surgeries, in hospitals, in anywhere, anywhere, a poster even ... they (women with PCOS) wouldn't feel isolated, they wouldn't feel embarrassed to ask for help or advice if it was more out in the open. It's all too hush, hush.' (Participant 2, age 44).

'It's probably a good idea to raise awareness (in schools) because there might be girls that have various symptoms and they either dismiss them or not actually affect them, it might just raise awareness.' (Participant 12, age 29).

\section{Discussion}

\section{Summary}

Participants reported a range of combined symptoms such as hirsutism, weight gain and infertility, which were likely to cause psychological distress. Delays in receiving a diagnosis were attributed to lack of knowledge in health care providers or their own reluctance to seek help. In addition to psychological distress, practical implications were described, particularly in terms of social interactions. Both practical and psychological coping strategies and support needs were reported and participants were generally positive about the idea of group education sessions for women with PCOS.

\section{Comparison with existing literature}

Our study confirms previous reports about the severity of PCOS and the negative impact it may have on womens' wellbeing, including high levels psychological distress, depression and anxiety $(8,18,19,20)$. Our findings also indicate that low self-esteem and low body image may have practical implications relating to social and personal interactions $(4,13,20,21)$. Previous authors have concluded that there is a need to provide information about diagnosis and also to help women with PCOS understand their condition $(22,23,24,25)$. It has been suggested that providing such information can improve wellbeing in women with PCOS (26). The need for psychological support and education was strongly confirmed by our findings, which emphasised the importance of providing such support and information at the time of diagnosis.

\section{Strengths and limitations}

This study adds to the literature in terms of including a specific focus on support needs and feelings about group education, whilst also using methodology that allowed scope for broader exploration of participants' experiences. In our sampling strategy and aims, we did not set out to specifically compare the views of women from different ethnic backgrounds, but recruitment from an ethnically diverse population enabled us to consider whether any of our findings were potentially specific to women from minority ethnic groups. Further research

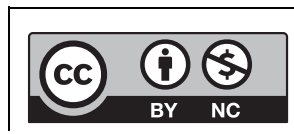

This work is licensed under a Creative Commons Attribution-NonCommercial 4.0 International License. 
exploring ethnic similarities and differences may be useful. It is acknowledged that our overall sample size was relatively small; however, large samples are not required for qualitative studies, but seek to highlight and explore relevant issues rather than to quantify perceptions in a representative sample. In addition, ongoing review during data collection suggested adequate saturation.

\section{Implications}

Our study provides some findings that are highly relevant to people involved in planning and providing care for women who have been diagnosed with or have symptoms suggestive of PCOS. Our interviews emphasise the need for a holistic approach by health care providers, including consideration of psychological needs as well as treatment for symptoms. Participants' positive attitudes to the idea of group education sessions indicate the potential acceptability of this method of providing support. Confirmation and further exploration of the impact of psychological distress emphasised that psychological support should be an important aspect of the content of such education sessions. As part of the refinement of the education programme being developed in this programme of work (14), additional emphasis was placed on support to reduce psychological distress and negative impact on the practicalities of day-to-day living. Our findings also suggest that the format of group education sessions may need to recognise differences as well as commonalities between women with PCOS, including cultural backgrounds, and that there may be some women who would need to be supported on an individual basis rather than through group sessions. There is a need for further education for health care providers to assist them with identifying the condition and equip them with skills and knowledge to be able to provide support effectively. There is also a need for education at community level to heighten general awareness and understanding of the condition, thereby fostering a more sympathetic attitude towards women with PCOS. Raised awareness could also help women to recognise possible symptoms and prompt them to seek help, leading to more timely diagnosis.

\section{Declaration of interest}

The authors declare that there is no conflict of interest that could be perceived as prejudicing the impartiality of the research reported.

\section{Funding}

The study was part of a PhD project (H M) which has been supported by Diabetes Research Centre, University of Leicester. The early stages of PhD project was partly supported by an 'Early Career Grant' from the Society for Endocrinology (H M).

\section{Author contribution statement}

Conception of the research question was by $H M, M J D, K K, M L$ and $M S$. Protocol of research was written by $\mathrm{H} \mathrm{M}$ and reviewed by all co-authors. Data collected by $\mathrm{H} \mathrm{M}$ and N P. M H, M S performed the data analysis and prepared the first draft of the paper. All authors have reviewed the manuscript.

\section{Acknowledgments}

The authors would like to thank all the participants who took part in our study and provided us with valuable and insightful information about their experiences of living with PCOS and their views about the provision of support. Authors acknowledge the support from the National Institute for Health Research Collaboration for Leadership in Applied Health Research and Care - East Midlands (NIHR CLAHRC - EM), the Leicester Clinical Trials Unit and the NIHR Leicester-Loughborough Diet, Lifestyle and Physical Activity Biomedical Research Unit, which is a partnership between University Hospitals of Leicester NHS Trust, Loughborough University and the University of Leicester. The views expressed are those of the authors and not necessarily those of the NHS, the NIHR or the Department of Health.

\section{References}

1 March WA, Moore VM, Willson KJ, Phillips DI, Norman RJ \& Davies MJ. The prevalence of polycystic ovary syndrome in a community sample assessed under contrasting diagnostic criteria. Human Reproduction 201025 544-551. (doi:10.1093/humrep/dep399)

2 McCook JG, Bailey BA, Williams SL, Anand S \& Reame NE. Differential contributions of polycystic ovary syndrome (PCOS) manifestations to psychological symptoms. Journal of Behavioral Health Services and Research 201542 383-394. (doi:10.1007/s11414013-9382-7)

3 Fauser BC, Tarlatzis BC, Rebar RW, Legro RS, Balen AH, Lobo R, et al. Consensus on women's health aspects of polycystic ovary syndrome (PCOS): the Amsterdam ESHRE/ASRM-Sponsored 3rd PCOS Consensus Workshop Group. Fertility and Sterility 201297 28.e25-38. e25. (doi:10.1016/j.fertnstert.2011.09.024)

4 Snyder BS. The lived experience of women diagnosed with polycystic ovary syndrome. Journal of Obstetric, Gynecologic, and Neonatal Nursing 200635 385-392. (doi:10.1111/j.1552-6909.2006.00047.x)

5 Mani H, Khunti K, Levy M \& Davies MJ. Diabetes advice for women with polycystic ovary syndrome: prevention, prevention, prevention. Diabetes Management 20133 467-480. (doi:10.2217/dmt.13.54)

6 Nasiri Amiri F, Ramezani Tehrani F, Simbar M, Montazeri A \& Mohammadpour Thamtan RA. The experience of women affected by polycystic ovary syndrome: a qualitative study from Iran. International Journal of Endocrinology and Metabolism 201412 e13612. (doi:10.5812/ ijem.13612)

7 Bishop SC, Basch S \& Futterweit W. Polycystic ovary syndrome, depression, and affective disorders. Endocrine Practice 200915 475-482. (doi:10.4158/ep09083.rar)

8 Jedel E, Waern M, Gustafson D, Landen M, Eriksson E, Holm G, et al. Anxiety and depression symptoms in women with polycystic ovary syndrome compared with controls matched for body mass index. Human Reproduction 201025 450-456. (doi:10.1093/humrep/ dep384)

9 Mani H, Levy MJ, Davies MJ, Morris DH, Gray LJ, Bankart J, et al. Diabetes and cardiovascular events in women with polycystic ovary syndrome: a 20-year retrospective cohort study. Clinical Endocrinology 201378 926-934. (doi:10.1111/cen.12068)

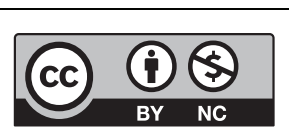


10 Dokras A. Mood and anxiety disorders in women with PCOS. Steroids 201277 338-341. (doi:10.1016/j.steroids.2011.12.008)

11 Veltman-Verhulst SM, Boivin J, Eijkemans MJ \& Fauser BJ. Emotional distress is a common risk in women with polycystic ovary syndrome: a systematic review and meta-analysis of 28 studies. Human Reproduction Update 201218 638-651. (doi:10.1093/humupd/dms029)

12 Kitzinger C \& Willmott J. 'The thief of womanhood': women's experience of polycystic ovarian syndrome. Social Science and Medicine (1982) 200254 349-361. (doi:10.1016/S02779536(01)00034-X)

13 Crete J \& Adamshick P. Managing polycystic ovary syndrome: what our patients are telling us. Journal of Holistic Nursing 201129 256-266. (doi:10.1177/0898010111398660)

14 Charmaz K. In Constructing Grounded Theory: A Practical Guide Through Qualitative Analysis. London, UK: Sage, 2007.

15 Statistics OfN. ONS 2015 (cited 201527 November 2015).

16 The Rotterdam sponsored PCOS consensus workshop group. Revised 2003 consensus on diagnostic criteria and long-term health risks related to polycystic ovary syndrome (PCOS). Human Reproduction 200419 41-47. (doi:10.1093/humrep/deh098)

17 Ritchie J \& Spencer L. Qualitative data analysis for applied policy research. In Analaysing Qualitative Data. Eds A Bryman \& R Burgess. London, UK: Sage, 1994

18 Barry JA, Kuczmierczyk AR \& Hardiman PJ. Anxiety and depression in polycystic ovary syndrome: a systematic review and meta-analysis. Human Reproduction 201126 2442-2451. (doi:10.1093/ humrep/der197)

19 Cinar N, Kizilarslanoglu MC, Harmanci A, Aksoy DY, Bozdag G, Demir B, et al. Depression, anxiety and cardiometabolic risk in polycystic ovary syndrome. Human Reproduction 201126 3339-3345. (doi:10.1093/humrep/der338)

20 Deeks AA, Gibson-Helm ME \& Teede HJ. Anxiety and depression in polycystic ovary syndrome: a comprehensive investigation. Fertility and Sterility 201093 2421-2423. (doi:10.1016/j. fertnstert.2009.09.018)

21 Bazarganipour F, Ziaei S, Montazeri A, Foroozanfard F, Kazemnejad A \& Faghihzadeh S. Body image satisfaction and self-esteem status among the patients with polycystic ovary syndrome. Iranian Journal of Reproductive Medicine 201311 829-836.

22 Dowdy D. Emotional needs of teens with polycystic ovary syndrome. Journal of Pediatric Nursing 201227 55-64. (doi:10.1016/j. pedn.2010.08.001)

23 Gibson-Helm ME, Lucas IM, Boyle JA \& Teede HJ. Women's experiences of polycystic ovary syndrome diagnosis. Family Practice 201431 545-549. (doi:10.1093/fampra/cmu028)

24 Mani H, Potdar N \& Gleeson H. How to manage an adolescent girl presenting with features of polycystic ovary syndrome (PCOS); an exemplar for adolescent health care in endocrinology. Clinical Endocrinology 201481 652-656. (doi:10.1111/cen.12501)

25 Mani H, Khunti K, Daly H, Barnett J \& Davies MJ. Education and selfmanagement for women with polycystic ovary syndrome; a narrative review of literature. Ibnosina Journal of Medicine and Biomedical Sciences $201571-9$.

26 Ching HL, Burke V \& Stuckey BG. Quality of life and psychological morbidity in women with polycystic ovary syndrome: body mass index, age and the provision of patient information are significant modifiers. Clinical Endocrinology 200766 373-379. (doi:10.1111/ j.1365-2265.2007.02742.x)

Received in final form 15 May 2017

Accepted 16 May 2017

Accepted Preprint published online 17 May 2017 http://www.endocrineconnections.org DOI: 10.1530/EC-17-0053
C 2017 The authors Published by Bioscientifica Ltd

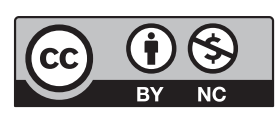

This work is licensed under a Creative Commons Attribution-NonCommercial 4.0 International License. 